\title{
Exploring Writing Errors Problems from EFL Lecturers' Perspectives at University Level
}

\author{
Abdurrahman M. Alfahadi \\ Department of English Languages and Translation, Faculty of Education and Arts, the University of Tabuk, Tabuk, Kingdom of \\ Saudi Arabia
}

$\triangle$ Corresponding Author: Abdurrahman M. Alfahadi, E-mail: aalfahadi@ut.edu.sa

\begin{tabular}{|c|c|}
\hline ARTICLE INFORMATION & ABSTRACT \\
\hline Received: December 22, 2020 & \multirow{7}{*}{$\begin{array}{l}\text { The purpose of this study was to identify the probable reasons for these spelling } \\
\text { errors form EFL lecturer's perspective and to tackle spelling problems. was hoped the } \\
\text { results would suggest remedial action the lecturers and the students might take to } \\
\text { address the problem of spelling. The findings revealed the main reasons for the } \\
\text { spelling errors made by Saudi university students which includes the interference of } \\
\text { Arabic when learning English, the nature of the English language itself, for instance, its } \\
\text { irregularity and limited rules, and other contextual effects like the inadequacy of the } \\
\text { university English language syllabus and classroom instructions in terms of teaching } \\
\text { spelling rules. The participants in this study suggested various possible strategies to } \\
\text { address the problem of spelling; for instance, academic intervention strategies such as } \\
\text { ways to engage the learners and pedagogical practices that could help EFL students } \\
\text { learn English better. }\end{array}$} \\
\hline Accepted: February 02, 2021 & \\
\hline Volume: 4 & \\
\hline Issue: 2 & \\
\hline DOI: 10.32996/ijllt.2021.4.2.13 & \\
\hline KEYWORDS & \\
\hline $\begin{array}{l}\text { Spelling errors, lectures, EFL } \\
\text { learners, group interview, learners' } \\
\text { errors }\end{array}$ & \\
\hline
\end{tabular}

\section{Introduction}

Learning a foreign language always involves a number of challenges especially in the initial phases of learning where learners make linguistic, syntactic, semantic, and phonological errors. James (2013) states that these errors are a by-product of learning the language and are indicators of learning; the level of such errors indicates the phase of learning the learners are at. Conducting a systematic analysis of learners' errors helps the understanding of their needs to learn the language in the best and fastest way.

University instructors can use the information gathered through the examination and assessment process to develop priorities for spelling instruction. At the same time, the outcomes and results of the students' spelling errors can also determine the English course syllabus requirements in order to improve the students' overall performance and efficiency in learning a second language (Fadda, 2012). It is necessary for the instructor to develop an assessment sheet for each student's achievement based on their currently developing skills together with the strategies to meet for their future proficiency needs (Daif-Allah, 2012). Furthermore, it is necessary for instructors to decide how the visual, phonological, etymological, and morphemic knowledge will be given through listening, talking or reading as well as writing. The four different forms of knowledge help the planning and execution of the appropriate learning activities and strategies. In addition, instructors need to select marking criteria and ways to indicate types of error which are clear to Saudi learners to help them understand their specific concerns with respect to English.

Furthermore, teachers should offer any additional support and encouragement needed by students during each learning phase. Teachers need to take account of any external factors like general tests and examinations to ensure students have provide the necessary skills, strategies, and knowledge, but more importantly, those that make the students more effective and successful learners. Regular classroom activities and language sessions must provide opportunities to deal with difficulties in reading, writing and spelling. Assessment and regular monitoring play a significant role in achieving better results and outcomes and help the instructor evaluate the performances of the students individually and see whether the students are making progress. Kang and Han (2015) argue that language instruction can increase the knowledge, skills and abilities of students to learn how to use

K C AL-KINDI CENTER

$\mathbf{R}$ D FOR RESEARCH AND $\mathbf{R}$ D DEVELOPMENT Your gateway to world-class research

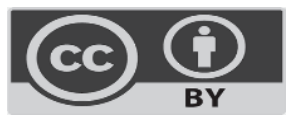

Published by Al-Kindi Center for Research and Development. Copyright (c) the author(s). This open access article is distributed under a Creative Commons Attribution (CC-BY) 4.0 license 
the appropriate rules in English language and thus use the language for study or work purposes. Teachers need to communicate through dialogue sessions with their students, as this is are considered critical for success.

Deacon (2017) investigated the causes of spelling errors by Arabic learners of English. He claimed that Arab learners of English make more errors in spelling vowels than consonants. Deacon's study analyses the reasons for short and long-vowel mistakes as well as the vowel and consonant error types from the writing compositions of Arab EFL students. The findings revealed that Arabic-speaker EFL learners make more vowel spelling errors than consonant errors. The results of his study also revealed that short vowels in Arabic were the main cause of vowel blindness in English, resulting in Arabic-speaker EFL learners having poorer spelling performance than other EFL learners. Although previous studies conducted on Writing Errors have revealed interesting findings, little attention so far has been paid to the analysis of these errors from EFL lecturer's perspective. Thus, the purpose of this paper is to explore how EFL Lecturers address spelling problems in Saudi Arabia.

\section{Research Methodology}

This qualitative research adopts and adapts the interpretive analysis design. It uses interview techniques as research instruments which includes 5 items for examining the elicited data in order to see the attitudes and views of the participants concerning the spelling errors. The use of textual analysis urges participants to give their illustration of their own attitudes and behaviours. Thus, the written text elicited in the process provides necessary data and information for interpretation and analysis (Cohen, Manion, \& Morrison, 2011). Qualitative study proposes that in social research an adequately selected and investigated sample can give a great contribution to the interpretation and analysis of the problem investigated. But when using questionnaire and interview research, the language used by the participants comprises a filter in which their setting is viewed. In connection, this research study uses written text and questionnaire surveys to formulate the answers without using technical terms but rather implying ordinary language. This is because providing responses in informal and colloquial language is somewhat interacted with formal setting which was considered the time of the analysis. The analysis of the findings included textual analysis and classification of responses as the focus was on participants as individuals.

The research also used structured group interviews with the instructors to gain collective and mutually shared information within the research context and boundaries. Group interviews were used in the study because they allow for a relaxed atmosphere which gives the students and tutors the confidence to share their opinion and thoughts freely and openly; it also provides a general point of view, thus saving, time and effort. Group interviews can generate more creative, new, and first-hand ideas that are sometimes missed in the study. The group interview can also combine questions and provide the opportunity to observe group norms and dynamics. The structured interviews helped the students and instructors to give direct answers to the research questions. 14 group interviews are used in this study for the students. In each group five there are five participating students. In addition, three group interviews were also used in this study for the lecturers, whereas in each group consist of five lecturers. The research participants used to be invited as groups into the department office in their free time to conduct the interview with them. While all the interviews were recorded and analysed manually.

\section{Results and Discussion}

\subsection{Theme 1: Poor Syllabus and Education System}

The lecturers from Group A, B and C expressed varied reasons for the causes of spelling errors made by the Saudi University students in writing compared to other EFL students. However, they were in agreement that the main cause was poor syllabus design and education system. For example, in the Saudi context, English is taught as a foreign language (EFL). Students are supposed to master the four language skills within English. Teaching the skill of writing, especially mastering the spelling component, is one of the major areas challenging language instruction and learning in Saudi EFL (LI/GA). The response points out that because English is a foreign language in Saudi Arabia it is difficult for students to gain expertise in all four skills, including spelling as the main component of the writing skill. The major challenges that are faced by learners are due to the teaching system especially teaching the skill of writing is one of the challenges that face Saudi students and lecturers. Another participant reported that, in some contexts, Saudi students are not able to master the four English language skills, especially in Tabuk University, because the students do not study writing as a compulsory subject, so this may be one of the reasons why Saudi students in Tabuk University face a problem with spelling (L2/GA). As pointed out by the lecturer, students could make spelling errors because of their University (Tabuk University) ignores the writing skill in the students' syllabus.

A participant from Group B shared that:

Saudi students do face more problems in English spelling than other learners. This is because they start studying English at a very late stage in school and in primary school, they are only taught in Arabic. English language is seen 
as a foreign language that is not as important as Arabic that can be because of Saudi cultures and traditions force students especially in the early stage of education (primary school) to master Arabic language rather any language.

$(\mathrm{L} 1 / \mathrm{GB})$

The response of above experts suggests that Saudi learners, compared with other EFL learners, often find it difficult to write in English. The reason behind this can be socio-demographic factors such as the timing and amount of English language training at an early stage, lack of resources, other obligations, including religious ones, and the relative unimportance of English etcetera. The above response suggests problems with learning may be due to Saudi culture and traditions, which mean people, tend to restrict their communication to Arabic and see no need for another language like English.

The responses reported by the lecturers are similar to the views of authors such as Krishnamurthy, Parameswaran, Seabolt and Wright (2016) and Hussain and Qamar, (2016). Their studies explored the various teaching frameworks in order to suggest various interventions to address students' specific learning needs in order to improve their spelling competence. These studies were conducted in different demographic regions but the findings were similar, which suggests that despite different backgrounds or regions, English learners often face difficulties while learning how to spell because of the different cultural background, poor education system, lack of skills and lack of resources provided at early stage, or just lack of motivation at all levels of the education system and administration.

In the Saudi context, English is taught as the foreign language (EFL), as an ordinary school subject. Saudi students and native speakers of languages like Chinese, Thai or Hindi, languages with a different writing system, face more challenges learning English writing and speaking skills than whose mother tongue uses a similar writing system to English, like French or Spanish. Hence, Saudi students generally do face more problems with English spelling than other learners because they have learned Arabic since childhood, which is totally different from English.

Another participant from Group B commented that, the Saudi government focuses on Islamic studies rather than on English. This is because Saudi Arabia is an Islamic country and they must keep the focus on Arabic rather than any other language. Again, this corresponds to one of the major root causes of spelling issues among Saudi students, as the government makes schools prioritize Islamic studies and Arabic rather than focusing on English language (L2/GB). The response of the lecturer suggests that because Saudi Arabia is an Islamic country, where the government and other agencies focuses on their religious values, they believe that Arabic is the only language which needs to be spoken as a means of communication throughout the country, therefore learning English has very little value. The learners have little motivation to acquire English competencies and are more likely to make spelling errors.

A participant from Group $C$ pointed out:

The textbook and course syllabus play a very important role in giving the students broad enough knowledge, especially in the first year of the BA program in the English department focusing on the basic skills of English language. In Tabuk University, the department of English language doesn't offer the students the opportunity to study the four English language skills as part of their studies; instead, the department offers different subjects in Arabic language in their first year. So it is clear reason for spelling errors because the students don't study writing or reading at all during their studies in the department.

\section{$(\mathrm{L} 1 / \mathrm{GC})$}

According to the above response, the students in Tabuk University are not provided with an opportunity to study any special courses in English in the first and second semester of the first year. They are only Arabic language courses. It seems that the major root cause of students spelling errors at the university stage of education is due to a lack of basic knowledge or foundation in English language, which has not been provided at an early stage of education.

\subsection{Theme 2: The Interference between English and Arabic Language}

Regarding the interference between English and Arabic, the lecturers from the different Groups shared different ideas for example; Saudi university students make spelling errors due to inter-lingual or intra-lingual errors. The inter-lingual errors start when students make spelling errors due to their native Arabic transfer. On other hand, their intra-lingual errors are because of poor learning of the second language ( $L 3 / G A$ ). The respondent suggests that inter-lingua and intra-lingual errors cause the students in Tabuk University to misinterpret English words and sentences. The students believe that because Arabic is their mother language and proficiency in it is most important, other languages are difficult for them. In this way, another language like English is not conceived as a means of communication, so the students of Tabuk University do not try to master any foreign language. 
Alhasiany (2014), Guzman-Orth, Grimm, Gerber, Orosco, Swanson and Lussier (2015), Hussain and Qamar (2016), and Botley and Dillah (2016) found that students in an Islamic country like Saudi Arabia are more focused on the Arabic language. Since education existed only for the few in Islamic schools when Saudi Arabia became independent in 1932, this is not surprising. Education is free today and any language other than English is not offered in the school curriculum and later education. English tends to be seen as another subject, like geography, not a means of communication. Previous reserchers like Alhaysony (2012) revealed that the inter-lingual or intra-lingual errors in their research were due to differences in the native and second language. Although the findings from past studies like Alhaysony (2012) were based on a different context, they were similar to the findings of this study, which suggest that the core reason behind inter-lingual or intra-lingual errors is due to defective teaching/learning of the students. The students in Tabuk University make spelling errors more often due to inter-lingual errors, due to mother-tongue interference, or intra-lingual errors, due to errors in learning the second language. Hence, the findings suggest that Saudi students' spelling make error while writing English due to misunderstandings about the target language; for instance, being unaware of spelling rules (e.g. $y$ singular country becomes ies in plural countries) or not knowing that one syllable words ending in a vowel and a consonant - like shop - the final consonant doubles before an ed or ing suffix > shopping, while one syllable words ending in a consonant and a vowel, drop the final vowel and keep the single consonant -hope > hoping. Silent letters, mentioned by the respondent below, can affect the pronunciation of the preceding vowel (like the difference in pronunciation between hop and hope) although they themselves are not pronounced.

Another comment regarding the interference between English and Arabic language shared by the lecturers, the nature of English language is also a cause of spelling errors. English is a difficult language, which is not easy to understand or learn. The main cause of students spelling errors is due to the number of silent letters. Also, the grouping of letters makes it hard for Saudi students to spell words when they compare it with Arabic (L3/GB). The response suggests that the nature of English language in terms of the silent letters or group of letters makes it hard for the students to understand how to spell words especially when the students compare it with Arabic. Silent letters also affect the pronunciation of the preceding vowel (like the difference between hop/hop/ and hope /houp/) although they themselves are not pronounced. Hence, members of the teaching staff find English is often difficult for Saudi students because the relationship between the spoken and written form is not straightforward as it is in Arabic; the function of the silent letter cannot be understood easily because there are none in Arabic and most of the students refer to their mother language rules while writing in English.

Another participant from Group B commented as shown below.

The interference between English and Arabic language in term of the differences in how certain vowels and consonants are pronounced makes English hard to understand and spell compared to Arabic, which has only three vowel sounds.

The response from the interviewee suggests that Tabuk University students find the differences in the functions vowels and the consonants in Arabic and English made it hard for them to gain proficiency in English, so they often feel demotivated about learning English. Perhaps the lecturers in Tabuk University could try various motivation and empowerment programs which help students to actively contribute to learning English language and perhaps collaborate with classmates to reduce spelling errors by sharing their knowledge about English spelling and pronunciation and how it differs from Arabic, so that Arabic does not remain their only model. Alhasiany (2014) and Botley and Dillah (2016) offer brief historical details about the distinctive nature of Arabic and English, which contribute to spelling errors in English.

The findings from past studies like Aljayosi (2001) are similar to the findings of this research, that the major reasons for spelling errors are due to lack of understanding of the link between speaking and spelling in English, poor concentration, overestimation of speed of learning, teachers' attitude to the importance of spelling and their medium of communication (Arabic or English) and consonant doubling errors. Although the context and unit of analysis in previous research have been different the research findings here are similar; in sum that mastering a foreign language is not easy and the distinctive nature of the Arabic and English languages present challenges to learners.

A participant from Group $\mathrm{C}$ added different comment regarding the differences between English and Arabic as a cause of students' spelling errors, Arabic impacts on English spelling because each has different ways of representing speaking. Firstly, the writing system of English has a significant impact on new learners. English and Arabic have totally different scripts. Arabic has regular spelling according to its pronunciation while English spelling is related to the origins of words as English is a hybrid language. The majority of the spelling errors by students are made due to mispronunciation (L3/GC). 
The findings from the above response suggest that students' spelling errors while learning English as foreign language are due to mispronunciation because English and Arabic are spoken and written in different ways; where Arabic has regular spelling according to its pronunciation, English has not. Arabic-speaking learners of English expect the same regularity or sound/symbol relationship that Arabic has. When they discover that this is not the case for English, they became confused and lose interest in learning English, because learning it seems more complex.

Another participant from Group C mentioned that:

In English, we have homophones, the same sounds, with different meanings and different spelling. This is a major difference between Arabic and English and causes the students to make spelling mistakes.

$(\mathrm{L} 5 / \mathrm{GC})$

The EFL students in Tabuk University find English homophones significantly contribute to misinterpretation and confusion, so students often misread words that have the same sound but different meanings. One suggestion is for homophones to be represented pictorially as well as written (as an aide memoire), that role play or simulation activities could direct the students in Tabuk University towards interactive, proactive learning techniques, rather than remaining the passive recipients of abstract knowledge.

The findings from the second theme (The interference between English and Arabic language) are in line with Hussain and Qamar (2016) and Botley and Dillah's (2016) studies, which share similar results about the spelling errors from examining the work of students learning English as a foreign language. Despite the different context and form of analysis, the findings from past studies concur with the present research conducted in Tabuk University that the Arabic language influences how Arabic speakers learn English speaking and writing because English and Arabic have different systems of speaking and writing.

\section{Conclusion}

Intervention at university level is crucial for improving the language skills of the students in the Kingdom of Saudi Arabia. Since the demographic area has Arabic as the prominent language, it is important to develop techniques and tactics at university level to improve the spelling of the students in English. The recommendations made will help Saudi universities to bring improvements to their curriculum so that the spelling errors of students can be tackled. These survey-based and research suggestions for education system of Saudi Arabia indicate that there is great need to put more emphasis on learning and writing English, especially the spelling, to access broader economic, educational and other knowledge, which English, as a global language, can provide.

\section{References}

[1] Aljafen, B. S. (2013). Writing anxiety among EFL Saudi students in science colleges and departments at a Saudi University. [Unpublished doctoral dissertation]. Indiana University of Pennsylvania.

[2] Alhaysony, M. (2012). An analysis of article errors among Saudi female EFL students: A case study. Asian Social Science, 8(12), 55-66.

[3] Botley, S. \& Dillah, D. (2016). Investigating spelling errors in a Malaysian learner corpus. Malaysian Journal of ELT Research, $3(1), 74-93$.

[4] Botley, S. \& Dillah, D. (2016). Investigating spelling errors in a Malaysian learner corpus. Malaysian Journal of ELT Research, 3(1), 74-93.

[5] Cohen, L., Manion, L., \& Morrison, K. (2011). Research Methods in Education (7th ed,). London: Routledge.

[6] Daif-Allah, A. S. (2012). Beliefs about foreign language learning and their relationship to gender. English Language Teaching, 5(10), 20-33.

[7] Fadda, H. A. (2012). Difficulties in academic writing: From the perspective of King Saud University postgraduate students. English Language Teaching, 5(3), 123-130.

[8] Kang, E. \& Han, Z. (2015). The efficacy of written corrective feedback in improving L2 written accuracy: A meta-analysis. The Modern Language Journal, 99(1), 1-18.

[9] Hussain, F. \& Qamar, U. (2016). In Proceeding ICEIS 2016 Proceedings of the 18th International Conference on Enterprise Information Systems, Rome, Italy, 25-28 April (pp. 333-338). Portugal: Science and Technology Publications. 